Volume 9, No.4, July - August 2020

International Journal of Advanced Trends in Computer Science and Engineering

Available Online at http://www.warse.org/IJATCSE/static/pdf/file/ijatcse327942020.pdf

https://doi.org/10.30534/ijatcse/2020/327942020

\title{
Mirror Microsoft Ml Network for Recognition and Organization of Objects in Law
}

\author{
Sergey G. Eremin ${ }^{1}$, Konstantin E. Lukichev ${ }^{2}$, Alexander M. Belyaev ${ }^{3}$, Irina I. Romashkova ${ }^{4}$, \\ Maria A. Khvatova ${ }^{5}$ \\ ${ }^{1}$ Federal state educational budgetary institution of higher education "Financial University under the Government \\ of the Russian Federation", Russia, SGEremin @fa.ru \\ ${ }^{2}$ Federal state educational budgetary institution of higher education "Financial University under the Government \\ of the Russian Federation", Russia, Lukichev.lk1@ gmail.com \\ ${ }^{3}$ Federal state educational budgetary institution of higher education "Financial University under the Government \\ of the Russian Federation", Russia, ABelyaev@fa.ru \\ ${ }^{4}$ Federal state educational budgetary institution of higher education "Financial University under the Government \\ of the Russian Federation", Russia, iiromashkova@fa.ru \\ ${ }^{5}$ Federal state budgetary educational institution of higher education " Bauman Moscow state technical University \\ (national research University) "(Bauman Moscow state technical University), Russia, Xvatovama@ rambler.ru
}

\begin{abstract}
In the article the features of construction of neural networks are studied, the main problems of neural networks are considered. To do this, the Android application was implemented and a series of experiments were conducted to identify the main features of neural networks. The following characteristics are assessed: the resources used to collect the project and the time it is debugged, productivity, and consumed resources. According to the results of the research the basic principles of the construction of specialized systems for working with neural networks have been formed.

Artificial neural networks are computing systems inspired by the biological neural network sthat make up the animal brain. Such systems learn tasks (progressively improve their performance on them) by looking at examples, generally without special programming for the task. For example, in image recognition, they can learn to identify images that contain cats by analyzing sample images labeled "cat" and "cat", and using the results to identify cats in other images. They do this without any prior knowledge of cats, for example, that they have fur, tails, whiskers and cat-like squeaks. Instead, they develop their own set of relevant characteristics from the training material they process.
\end{abstract}

Key words : Byte code, neural network, compiler, machine learning, design optimization.

\section{INTRODUCTION}

Ins is based on a set of connected nodes, called artificial neurons (similar to biological neurons in the brain of animals) [1-4]. Each connection (similar to a synapse) between artificial neurons can transmit a signal from one to the other [5]. An artificial neuron that receives a signal, processes it, and then signals to the artificial neurons attached to it [6-9].
In common ins implementations, the signal at the junction between artificial neurons is a real number, and the output of each artificial neuron is calculated by a nonlinear function of the sum of its inputs [10-12]. Artificial neurons and connections usually have weights that are adjusted during training [13]. Weight increases or decreases the signal strength on the connection. Artificial neurons can have such a threshold that a signal is sent only if the aggregate signal crosses this threshold [14]. Artificial neurons are usually organized in layers. Different layers can perform different types of transformations of their inputs. Signals pass from the first (input) layer to the last (output) layer, possibly after passing the layers several times [15].

The primary purpose of the ins approach was to solve problems in the same way that a human brain would. Over time, attention focused on matching certain mental abilities, leading to deviations from biology. Ins were used in a number of different tasks, including computer vision, speech recognition, machine translation, social network filtering, playing Board and video games, and medical diagnostics.

\section{MATERIALS AND METHODS}

Artificial neural networks are not programmed in the usual sense of the word, they are trained. Learning capability is one of the main advantages of neural networks over traditional algorithms. Technically, learning consists of finding the coefficients of connections between neurons. In the process of learning, the neural network is able to identify complex dependencies between inputs and outputs, as well as perform generalization [16-19].

For the learning process, it is necessary to have a model of the external environment in which the neural network functions - the necessary information for solving the problem. Secondly, you need to determine how to modify the network's weight parameters. (fig. 1) 


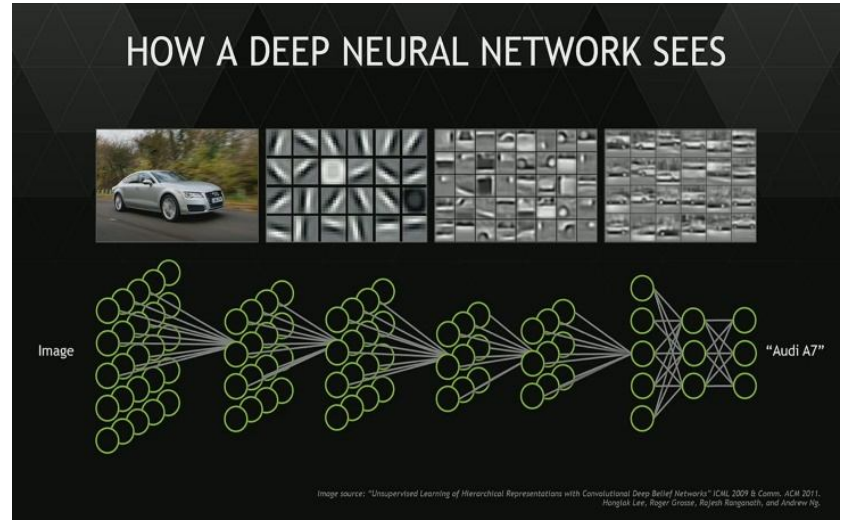

Figure 1: Principle of training neural networks

There are three General paradigms of learning: "with a teacher", "without a teacher" (self-learning) and mixed. In the first case, the neural network has at its disposal the correct answers (network outputs) to each input example [20]. Weights are configured so that the network produces responses closest to the known correct answers. Learning without a teacher does not require knowing the correct answers to each sample of the training sample. In this case, the internal data structure and correlation between samples in the training set are used to distribute samples into categories. In mixed learning, part of the balance is determined by the help of teaching with the teacher, while the other part is determined by the help of self-learning [21].

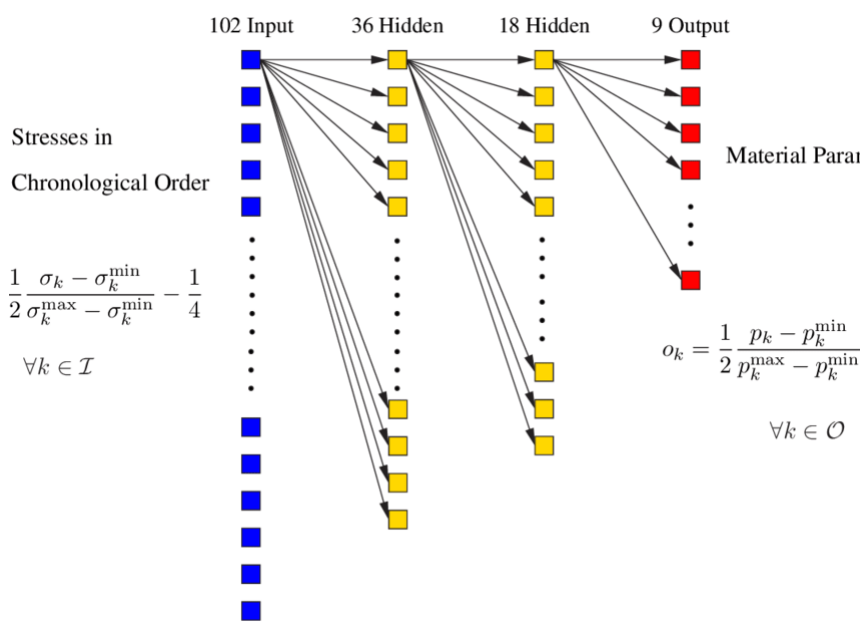

Figure 2: Stress-test in neural network

Figure 2 shows us stress-test in neural network.

Neural networks have a wide range of applications [22]:

- Pattern recognition and classification. Images can be objects of a different nature: text symbols, images, sound samples, and so on. When training the network, various samples of images are offered with an indication of which class they belong to. When a certain image is presented to the network, one of its outputs should show a sign that the image belongs to this class. At the same time, other outputs must indicate that the image does not belong to this class.
- Decision-making and management. This task is close to the classification task. Situations whose characteristics are transmitted to the input of the neural network should be classified. The network output should show a sign of the decision that it has made.

- Clustering. Clusterization refers to splitting a set of input signals into classes, even though neither the number nor the attributes of the classes are known in advance. After training, such a network is able to determine which class the input signal belongs to.

- Forecastings. The ability of a neural network to predict results directly from its ability to generalize and highlight hidden dependencies between input and output data. After training, the network is able to predict the future value of a certain sequence based on several previous values or some currently existing factors.

- Data compression and associative memory. The ability of neural networks to detect relationships between different parameters makes it possible to Express large-dimensional data more compactly if the data is closely interconnected. The reverse process-restoring the original data set from a piece of information - is called associative memory.

The obtained results are planned to be used in future studies, which will be devoted to the definition of objects in neural systems [23].

The study also revealed the main drawback of apk archives generated by the standard Manager, which allows you to ensure the reliability of the system, generate Kotlin code classes in JavaScript scripts and use them in Web technologies .it works under the Android OS only for $60 \%$ of the total amount. Using the example of a system that interacts with Firebase cloud resources, a number of threats were identified that the Android application can respond to. These threats include decompiling bytecode, listening to Internet connections with the server, and intercepting user data [24].

Summing up the above, we can suggest the following steps for the development of this direction [25]:

- comparison of system characteristics with the use of ProGuard utility and on-demand updates ProGuard;

- developing methods to protect the integrity of Android applications;

- enhancing the noise immunity of Java code intended for Android systems;

These issues and problems will be widely applied and developed in the future, based on the current picture of the security problem in Android systems [26].

The factors generalized in the indices are defined as the factors influencing the financial result of business processes: x1 - Networked readiness Index; x2 - ICT Development Index; $\mathrm{x} 3$ - global competitiveness index. 


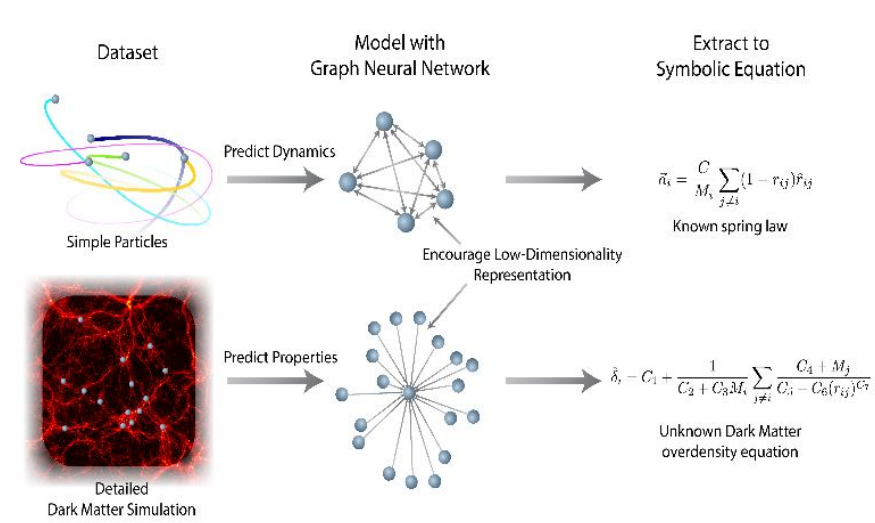

Figure 3: Deep learning model for neural network

Figure 3 shows us deep learning model for neural network. Low indicators of network readiness, level of ICT development, global competitiveness of the domestic economy and profitability of business are established. In addition, these indicators in the dynamics do not have a significant increase and a significant impact on economic growth in the analyzed period [27-30]. According to current data, management measures in the complex of network readiness and ICT development index, as well as ICT development indices and global competitiveness are appropriate to increase the efficiency of business processes. According to the simulated situations, the obtained results made it possible to prove the convergence of the resulting indicator with respect to independent factors. The algorithm of application of a technique of an estimation of functioning of business with use of neural network technologies is offered in work. Within the limits of the presented algorithm the target priority of the regulator of a choice of the most optimum method of the analysis and data processing is actualized.

\section{CONCLUSION}

In this article, a study was conducted on the construction of neural systems, their training and maintenance. Possible problems in the development of the neural system architecture and its design in the General application system are identified.

For research purposes an application was developed for interaction with external resources using the Internet and Microsoft ML Kit technology We used the latest synchronization and network access tools, namely Retrofit 2.0 and the latest obfuscation tools available in the latest version of ProGuard.

Research results have shown that projects that use a neural network are $87 \%$ faster and $79 \%$ more reliable.

In addition to qualitative characteristics, the reliability of the system is doubled, which makes it impossible to decompile the project, reuse the code and provides a high level of protection for all user data..

\section{REFERENCES}

1. Boguslavskii M.M. International Private Law: a textbook. M.: Norma. 2005. p. 16.
2. Voinikanis E.A. The paradigm shifts in modern law / Philosophy of politics and law. M., 2010. Vol. 1. P. 138-161.

3. Gavrilov V.V. The concept of national and international legal systems // Journal of Russian law. 2004. No. 11. P. 98-112.

4. Zonova T.V. NGOs will remain in the future? / INF: 05.11.2013 URL:

http://russiancouncil.ru/inner/?id_4=2628\#top (accessed date 11.11.2018)

5. Israelian E.V. The dialogue between the state and the public: the experience of Canada / M.: Institute of the USA and Canada RAS, 2006. P.59-60

6. Lazebnik L.L. International financial law: Ucheb.pos. - C: Center for educational literature, 2018. - P.18.

7. Lebedeva M.M. Actors of modern world politics: development trends / MGIMO Bulletin. M: 2013. Number 3 (28). P. 38-42.

8. Lukashuk I.I. Rules of international law in the international regulatory system. M., 1997. P. 124.

9. Podshibiakin S.A. The legal status of international non-governmental organizations / Author's abstract. M: MGIMO, 2004. URL:

http://www.dissercat.com/content/pravovoi-status-mezh dunarodnykhnepravitelstvennykh-organizatsii (accessed date 3.11.2018)

10. Council of Europe. Convention on the recognition of legal entities of international non-governmental organizations / ETS N 124. Strasbourg, April 24, 1986.

11. Chirkin V.E. Global legal systems, legal families and their classification // Law. Journal of Higher School of Economics. 2017. No. 4. P.18-30.

12. Shumilov V.M., International financial law: a textbook. M.: International Relations, 2015. - P.40.

13. Entin $M$. Challenges of time and a new vision of international, supranational and domestic law / $\mathrm{M}$. Entin // Electronic resource. - Access mode. http://alleuropalux.org/?p=2514

14. Basic Facts about ECOSOC Status. / NGO Branch. Department of Economic and Social Affairs. URL: http:// csonet.org/? menu=100 (Accessed 10/11/2018)

15. Boyle A. E. Some reflections on the relationship between treaties and soft law / ASIL Conference on Multilateral Treaty-Making Geneva, 1998 (Graduate Institute of International LAW).

16. Decaux, Emmanuel. Droitinternational public. - Paris: DALLOZ, 2008. - $452 \mathrm{p}$.

17. Kirton J. (2010) Multilateral Organizations and G8 Governance: A Framework for Analysis // Making Global Governance Effective: Hard and Soft Law Institutions in a Crowded World / J. Kirton, M. Larionova, P. Savona (eds). Farnham: Ashgate Ledomandedi'esame di DirittoInternationalePubblico. Collaborazione di dott. ssaGiovannaCammilli. - Napoli: Simone, 2009. - 304 p.

18. Prokofiev, Stanislav E. et al. 2018. Professional Development of Civil Servants of Russia: Legal and Organizational Aspect, Journal of Advanced Research in Law and Economics, Volume IX, Spring, 1(31): 234 - 
241. DOI: 10.14505/jarle. v9.1(31).28. Available from: http://journals.aserspublishing.eu/jarle/index

19. Ruchkina, Gulnara et al. 2018. Norms of Soft Law as a New Source of Financial Law of Russia, Journal of Advanced Research in Law and Economics, Volume IX, Spring, 1(31): 278 - 286. DOI:10.14505/jarle. v9.1(31).33. Available from: http://journals.aserspublishing.eu/jarle/index

20. Ruchkina, Gulnara et al. 2018. Norms of Soft Law as a New Source of Financial Law of Russia, Journal of Advanced Research in Law and Economics, Volume IX, Spring, 1(31): $278-286$.

DOI:10.14505/jarle.v9.1(31).33. Available from: http://journals.aserspublishing.eu/jarle/index

21. Salamon, 1., Sokolowski, S., List, R. Global Civil Society. An Overview/The Johns Hopkins University Institute for Policy Studies, 2003. P. 1.

22. Burov A.G., Agüero D. Implementation of the Principles of Innovative Entrepreneurship in the Field. Academy of Entrepreneurship Journal. 2019. Vol. 25. Issue 1S. pp. 1-5.

23. Klyuev S.V., Bratanovskiy S.N., Trukhanov S.V., Manukyan H.A. Strengthening of concrete structures with composite based on carbon fiber // Journal of Computational and Theoretical Nanoscience. 2019. V.16. №7. P. 2810 - 2814.

24. Shashkova, A. (2019). Regulating principles of disclosure of information to shareholders under G20 / OECD principles. In Proceedings of the 33rd International Business Information Management Association Conference, IBIMA 2019: Education Excellence and Innovation Management through Vision 2020 (pp. 1931-1936).

https://doi.org/10.2139/ssrn.3504757

25. Koshkin, A. P., Abramov, R. A., Rozhina, E. Y., \& Novikov, A. V. (2018). Role of Social Representations in Student Motivation for Acquiring Further Education. Interchange, 49(3), 313-341. https://doi.org/10.1007/s10780-018-9328-3

26. Lubysheva, L. I., \& Abramov, R. A. (2014). Innovative model of olympic education of primary schoolchildren based on information and communication technologies. Teoriya i Praktika Fizicheskoy Kultury, (7), 87-89.

27. Kolganova, I. S., \& Taran, S. S. (2019). Usage practicability of acer $\mathrm{l}$. Species in landscaping in the central part of Rostov region. World Ecology Journal, 9(2), 95-105.

https://doi.org/10.25726/worldjournals.pro/WEJ.2019.2.5

28. Huzhahmetova, A. S. (2019). Analysis of the habitats of the genus Corylus $L$. proclamations and their seasonal patterns of fruiting. World Ecology Journal, 9(2), 106-118.

https://doi.org/10.25726/worldjournals.pro/WEJ.2019.2.

29. Viana, J. H. F., Costa, J. O., Nilson, I. C., Freitas, D. C. C., \& Silva, H. S. (2019). Discharge curve analysis of a lead-acid battery model. International Journal of Advanced Trends in Computer Science and Engineering, 8(1), 325-330. https://doi.org/10.30534/ijatcse/2019/5781.12019
30. Victoriano, O. B., \& Fajardo, A. C. (2020). Modified ensemble of pruned set for non-linear dataset. International Journal of Advanced Trends in Computer Science and Engineering, 9(1.1 Special Issue), 47-50. https://doi.org/10.30534/ijatcse/2020/0991.12020 